\title{
Bioaccumulation of Cadmium, Copper, Lead, and Zinc in Water Buffaloes (Bubalus bubalis) Infected with Liver Flukes (Fasciola gigantica)
}

\author{
ADRIAN GABRIEL D. ACOSTA ${ }^{1}$, CAMILLE NOELLE M. CAMARA ${ }^{1}$ \\ JUAN ROCCO MARTIN J. ONGSIAKO', JOACHIM N. TSOI ${ }^{1}$ \\ MARY JANE C. FLORES ${ }^{1}$, JOSE ISAGANI B. JANAIRO' \\ JOSE SANTOS R. CARANDANG VI', RODANTE G. FLORES ${ }^{2,3}$, DIVINA M. AMALIN ${ }^{1}$, \\ NANCY S. ABES ${ }^{1,4}$ and DERICK ERL P. SUMALAPAO ${ }^{1,5,6, *}$ \\ 'Department of Biology, College of Science, De La Salle University, Manila, Philippines. \\ ${ }^{2}$ Philippine State College of Aeronautics, Pasay City, Philippines. \\ ${ }^{3}$ Graduate Studies Department, College of Science and Computer Studies, De La \\ Salle University-Dasmariñas, Cavite, Philippines. \\ ${ }^{4}$ Philippine Carabao Center, Nueva Ecija, Philippines. \\ ${ }^{5}$ Mathematics Area, School of Multidisciplinary Studies, De La Salle-College of \\ Saint Benilde, Manila, Philippines. \\ ${ }^{6}$ Department of Medical Microbiology, College of Public Health, University of \\ the Philippines Manila, Manila, Philippines. \\ *Corresponding author E-mail: derick.sumalapao@ dlsu.edu.ph \\ http://dx.doi.org/10.13005/ojc/330412
}

(Received: June 16, 2017; Accepted: July 13, 2017)

\begin{abstract}
Exposure of living organisms to heavy metals can lead to bioaccumulation and can have some detrimental health effects. This study identified the species of liver flukes present in the liver tissues of water buffaloes, determined the concentration and bioconcentration factor of cadmium, copper, lead, and zinc present in both the liver tissues and liver flukes using atomic absorption spectrophotometry. Of the 1,329 liver flukes extracted from the 14 livers, Fasciola gigantica ( $F$.gigantica) was the only species present in the collected liver tissues. The median heavy metal concentrations $(\mu \mathrm{g} / \mathrm{g})$ in the liver tissues were $0.93,9.13,4.75$, and 48.95 for cadmium, copper, lead, and zinc, respectively. F. gigantica had median heavy metal concentrations $(\mu \mathrm{g} / \mathrm{g})$ of $3.32,72.26,20.82$, and 159.37 for cadmium, copper, lead, and zinc, respectively. Both the liver tissues and F. gigantica were identified to contain varying concentrations of these heavy metals $(p<0.05)$. The presence of these heavy metals in both the liver tissues and $F$. gigantica suggests heavy metal contamination of the areas where the carabaos graze. The bioconcentration factors for cadmium, copper, lead, and zinc were greater than 1.0 indicating that liver flukes are good bioaccumulators and bioindicators of environmental pollution.
\end{abstract}

Keywords: Fasciola gigantica, Atomic absorption spectrophotometry, Heavy metals, Bioaccumulation, Bioindicator, Bioconcentration factor. 


\section{INTRODUCTION}

Heavy metals are found in ample amounts in the environment due to its abundant use in industrial factories. Exposure of humans and animals via inhalation or ingestion to these heavy metals can have detrimental consequences to health. The toxicities of these heavy metals vary depending on the dose, route of exposure, and chemical species, as well as the age, gender, genetics, and nutritional status of exposed individuals ${ }^{1}$. However, some studies indicated that certain organisms accumulate toxins at certain levels without any harmful health effects, whereas for Fasciola gigantica (F. gigantica), high exposure to lead results to tegumental deformities such as crumpling and blebbing ${ }^{2}$.

Many livestock animals such as sheep and ruminants, particularly cattle, are prone to parasitic infections. Due to the quality of a parasite's ability to bioaccumulate heavy metals in its system, these parasites may serve as potential indicators of environmental quality ${ }^{3}$. Parasitic flatworms belonging to Phylum Platyhelminthes, Class Trematoda require intermediate and definitive hosts to complete its life cycle $^{4}$. Examples of common parasites infecting ruminants belonging to Class Trematoda are Fasciola hepatica and Fasciola gigantica commonly known as liver flukes. These liver flukes cause fascioliasis or fasciolosis, a condition wherein the liver is infected by either or both Fasciola making them economically significant ${ }^{5}$. Moreover, fascioliasis is a zoonotic condition where parasites infecting animals can be transmitted to humans. Recent studies show that the two species are increasing in Europe, United States of America, Oceania, Africa, and Asia ${ }^{6}$. Other examples of these parasites are the intestinal acanthocephalans, nematodes, and cestodes which can accumulate heavy metals present in the environment.

Bioaccumulation of heavy metals in a trophic level may be passed on to higher trophic levels in significantly increasing amounts and can be introduced into new environments ${ }^{7}$. A trophic level is a part of a functioning biological community that is composed of various organisms such as primary producers, preys, and predators ${ }^{8}$. In the case of organisms at a higher trophic level that consume its prey having accumulated heavy metal, the predator can break down the heavy metal leading to absorption in its body. Thus, this makes the present study relevant in determining the presence of heavy metals in the liver flukes as well as in the liver tissues of water buffaloes as these serve as bioindicators. Since humans consume water buffalo products, liver tissues may be studied as bioindicators. Due to these problems involving heavy metals and liver flukes, this study determined and compared the concentrations of heavy metals, namely cadmium, copper, lead, and zinc in both water buffalo liver tissues and liver flukes, and determined the potential of the liver flukes as bioaccumulator and bioindicator.

\section{MATERIALS AND METHODS}

\section{Collection of Samples and Spieces Identification}

Fourteen infected livers were collected from slaughtered water buffaloes in the Veterinary Inspection Board located in Tondo, Manila, Philippines. The liver samples were immediately transported to the Zoology and Parasitology Laboratory, Science and Technology Research Center, De La Salle University. Liver samples were then processed for extraction of the liver flukes and the collected flukes were placed in petri dishes for further analysis. Species identification of liver flukes was based on morphological characteristics ${ }^{6}$.

\section{Heavy Metal Concentration Determination}

The collected liver tissue and liver fluke samples were digested in $6.0 \mathrm{~mL}$ of $30 \%$ hydrogen peroxide and $12.0 \mathrm{~mL}$ of $60 \%$ nitric acid, and subsequently heated at around $35-40{ }^{\circ} \mathrm{C}$ until no observable material is left ${ }^{9}$. The samples were then filtered and the filtrate obtained was diluted to $100 \mathrm{~mL}$ distilled water. The diluted samples were then kept in amber bottles until atomic absorption spectrophotometric analysis was conducted.

Standards of $0.125,0.250,0.500$, and 1.000 ppm were separately prepared for cadmium, copper, lead, and zinc. Spectrophotometric analysis of each metal was carried out using Shimadzu6700 spectrophotometer. In each run, triplicate measurements of the metal concentration were obtained for each of the heavy metals in both the liver tissue and liver fluke samples. 


\section{Data and Statistical Analysis}

Heavy metal concentrations $(\mu \mathrm{g} / \mathrm{g})$ were reported as median \pm interquartile range. Nonparametric tests were employed to analyze the obtained experimental data. Comparisons on the heavy metal concentrations between liver tissue and liver fluke samples were performed using median test and two-sample Wilcoxon rank-sum (Mann-Whitney) test. Assessment on the differences in the bioindicator level and bioconcentration factor was done using Kruskal-Wallis equality of population rank test. All statistical analyses were performed at $1 \%$ level of significance using STATA $®$ V12.0.

\section{RESULTS AND DISCUSSION}

A total of 1,329 liver flukes were extracted from 14 water buffalo livers and all were identified as F. gigantica. These liver flukes were prevalent in the tropical areas and Southeast Asia including the Philippines ${ }^{10}$. Only F. gigantica was identified to infect water buffaloes ${ }^{11}$, but can also co-exist with Fasciola hepatica $^{12}$.
Spectrophotometric studies on liver tissue and liver fluke samples revealed presence of varying concentrations of cadmium, copper, lead, and zinc (Table 1). These heavy metal concentrations were found to be consistently higher in the liver fluke samples compared to the liver tissue samples where these flukes were extracted (Table 1). Zinc has the highest concentration, in both the liver tissue and liver fluke samples, among the four heavy metals identified in this study $(\mathrm{Zn}>\mathrm{Cu}>\mathrm{Pb}>\mathrm{Cd})$. The liver tissue and liver fluke samples differ with respect to their levels of heavy metal concentrations $(p<0.001$, Table 2). Consequently, the significant differences in concentrations of each of the heavy metals in the liver tissue and liver fluke samples resulted to variations in the bioconcentration factor levels of these heavy metals $\left(p=0.0026, X^{2}=14.253, \mathrm{df}=3\right.$, Table 3).

The bioconcentration factor (BCF) reflects the transfer of a heavy metal from the liver tissue to liver flukes, and was obtained by dividing the concentration of a heavy metal measured in the parasite's tissue with the concentration of the same

Table 1: Heavy metal concentrations $(\mu \mathrm{g} / \mathrm{g})$ in the liver tissue and liver fluke samples

\begin{tabular}{lllll}
\hline & \multicolumn{4}{l}{ Heavy metal concentration, median \pm interquartile range $(\boldsymbol{\mu g} / \mathbf{g})$} \\
& Cadmium & Copper & Lead & Zinc \\
\hline Samples & & & & \\
Liver tissues & $0.9300 \pm 0.4040$ & $9.1290 \pm 9.6160$ & $4.7480 \pm 3.6940$ & $48.9540 \pm 5.1360$ \\
F. gigantica & $3.3158 \pm 1.1754$ & $72.2588 \pm 44.1052$ & $20.8246 \pm 26.0351$ & $159.3684 \pm 69.1140$ \\
\hline
\end{tabular}

Table 2: Median and Mann-Whitney tests on heavy metal concentrations between the liver tissue and liver fluke samples

\begin{tabular}{lllll}
\hline & \multicolumn{4}{c}{ Heavy Metal } \\
& Cadmium & Copper & Lead & Zinc \\
\hline Median Test & & & \\
Pearson X & & & \\
p-value & 28.000 & 20.5714 & 20.5714 & 20.5714 \\
& 0.0000 & 0.0000 & 0.0000 & 0.0000 \\
Mann-Whitney Test & & & & \\
Rank sum & & & & \\
Liver tissues & 105 & 109 & 111 & 117 \\
F. gigantica & 301 & 297 & 295 & 289 \\
Z-statistic & -4.505 & -4.319 & -4.228 & -3.952 \\
$p$-value & 0.0000 & 0.0000 & 0.0000 & 0.0001 \\
\hline
\end{tabular}


Table 3: Kruskal-Wallis equality of metals concentration rank test on bioconcentration factor

\begin{tabular}{|c|c|c|c|c|}
\hline & \multicolumn{3}{|c|}{ Heavy Metal } & \multirow[b]{2}{*}{ Zinc } \\
\hline & Cadmium & Copper & Lead & \\
\hline $\begin{array}{l}\text { Bioconcentration factor } \\
\text { Median } \pm \text { IQR }\end{array}$ & $3.6484 \pm 1.201$ & $7.9332 \pm 5.7436$ & $4.3860 \pm 1.8657$ & $3.3914 \pm 1.330$ \\
\hline Rank sum & 309 & 559 & 456 & 272 \\
\hline
\end{tabular}

IQR: interquartile range

heavy metals in the liver tissue where the parasite was extracted ${ }^{13}$. All the heavy metals identified in this study had BCF values greater than 1.0 (Table 3). Copper has the highest BCF value compared to other heavy metals $(\mathrm{Cu}>\mathrm{Pb}>$ $\mathrm{Cd}>\mathrm{Zn}$ ). With these results, the authors identified that liver flukes accumulated higher concentrations of these heavy metals than their respective hosts. This indicates the indirect impacts of the biotic effects of pollutants ${ }^{14}$. Hence, it can be ascertained that these liver flukes can serve as potential bioindicators in assessing the current conditions of an ecosystem.

\section{CONCLUSION}

Fasciola gigantica accumulated higher concentrations of heavy metals when compared to liver tissues where these liver flukes were extracted. These liver flukes can serve as bioaccumulators and bioindicators of environmental pollution. Considering how these concentrations of heavy metals in the flukes and tissues can be associated with the area where the water buffaloes were fed, certain mitigation measures particularly rehabilitation of the area in case of heavy metal contamination should be in place. Likewise, it is recommended that the pastureland where the water buffaloes graze should be tested for the presence of other heavy metals. Furthermore, knowledge about heavy metal contamination in the adjacent trophic levels such as grass or plants which serve as food for the water buffaloes is significant due to possible adverse effects on human health.

\section{REFERENCES}

1. Tchounwou, P.; Yedjou, C.; Patlolla, A.; Sutton, D. Heavy metal toxicity and the environment. A. Luch (ed.), Molecular, Clinical and Environmental Toxicology, Experientia Supplementum. 2012, 101,133-164.

2. Chang, A.C.G.; Flores, M.J.C. Tegumental studies of adult Fasciola gigantica (giant liver fluke) from Philippine Carabaos (Bubalus bubalis) using scanning electron microscopy for lead bio-indicator analysis. Manila Journal of Science. 2015, 11.

3. Lotfy, W.; Ezz, A.; Hassan, A. Bioaccumulation of some heavy metals in the liver flukes Fasciola hepatica and F. gigantica. Iranian Journal of Parasitology. 2013, 8, 552-558.

4. Fried, B.; Graczyck, T.K. Advances in trematode biology. Boca Raton: CRC Press, 1997.

5. Phalee, A.; Wongsawad, C.; Rojanapaibul,
A.; Chai, J.Y. Experimental life history and biological characteristics of Fasciola gigantica (Digenea: Fasciolidae). The Korean Journal of Parasitology. 2015, 53(1), 59-64.

6. World Health Organization (WHO). Fascioliasis. Retrieved 2016 Oct 17 from http://www. who.int/ foodborne trematode_infections/ fascioliasis/en/.

7. Mitchell, K. The transfer of heavy metals through trophic levels and their toxicity effects on organisms including humans. Nottingham Trent University's Institutional Repository. 2007.

8. Branca, B.; Focazio, P.; Dunn, K. Heavy metal in the food chain. 2011. Retrieved 2017 June 1 from http://www.seagrant.sunysb.edu/images/ uploads/pdfs/cl-spr11.pdf.

9. Furukawa, J. Nitric acid digestion protocol. University of Tsukuba. Retrieved from 
https://www.plantcellwall.jp/protocol/pdf/ protocol_10.pdf, 2013.

10. Saleha, A.A. Liver fluke disease (fascioliasis): Epidemiology, economic impact, and public health significance. Southeast Asian J Trop Med Public Health. 1991, 22, 361-364.

11. Chang, A.C.G.; Flores, M.J.C. Morphology and viability of adult Fasciola gigantica (giant liver flukes) from Philippine carabaos (Bubalus bubalis) upon in vitro exposure to lead. Asian Pacific Journal of Tropical Biomedicine. 2015, 5(6), 493-496.

12. Aguila, J.A.; Saldonido, G.B. Trace metal analysis of copper $(\mathrm{Cu})$ and lead $(\mathrm{Pb})$ in water buffaloes (Bubalus bubalis) infected with liver flukes. [undergraduate thesis], De La Salle University. 2015.

13. Satpathy, D.; Reddy, M.V.; Dhal, S.P. Risk assessment of heavy metals contamination in paddy soil, plants, and grains (Oryza sativa L.) at the East Coast of India. BioMed Research International. 2014, 1-11.

14. Holt, E.A.; Miller, S.W. Bioindicators: using organisms to measure environmental impacts. Nature Education Knowledge. 2010, 3(10), 8. 